\title{
ON MEASURES OF NATURAL RESOURCE SCARCITY
}

\author{
Anthony C. Fisher
}

\author{
RR-77-19
}

August 1977

Research Reports provide the formal record of research conducted by the International Institute for Applied Systems Analysis. They are carefully reviewed before publication and represent, in the Institute's best judgment, competent scientific work. Views or opinions expressed therein, however, do not necessarily reflect those of the National Member Organizations supporting the Institute or of the Institute itself.

International Institute for Applied Systems Analysis

A -2361 Laxenburg, Austria 



\section{PREFACE}

At least since the "energy crisis" of the early 1970s there has been very substantial concern, both popular and scientific, for the future adequacy of the natural resource base of advanced industrial economies. This is reflected at IIASA in the research programs in Energy, Food and Agriculture, and Water. Within the System and Decision Sciences Area, one research task focuses on the allocation of resources over long periods of time by markets and other mechanisms, with particular reference to the non-reproducible natural resources.

This report studies the properties of a number of suggested measures of natural resource scarcity and their behavior as a resource is depleted over time. It is based in part on a conference on natural resource scarcity held at Resources for the Future in 1976, and will appear in somewhat different form in. the conference proceedings. 



\section{On Measures of Natural Resource Scarcity}

\section{INTRODUCTION: PHYSICAL AND ECONOMIC SCARCITY}

The widely publicized predictions of impending scarcity, and even exhaustion, of extractive natural resources like metals and fuels in the Club of Rome study, The Limits to Growth (1972), and the less widely publicized rebuttals (see for example Beckerman, 1972, Nordhaus, 1973b, and Kay and Mirrlees, 1975) suggest that a careful analysis of what is meant by resource scarcity, and how it is measured or indicated, might be worth while. The object of this paper is to provide such an analysis. specifically, I shall consider in this section the meaning of scarcity, and in subsequent sections a number of proposed measures; their properties; and their behavior as a resource stock is depleted--or, in a sense I shall presently suggest, augnented--over time.

Perhaps the question, what is scarcity? is too simple for economists, too simple to be made explicit, at any rate. We ordinarily say a good--or a resource--is scarce if the quantity demanded exceeds the quantity supplied at some benchmark price, such as the prevailing one, so that there is, in a competitive market, upward pressure on the price. As a special case, goods are sometimes considered scarce, or "economic", as opposed to "free", if this excess demand is positive at a zero price. But much of the current debate about natural resource scarcity focuses on physical measures, such as the stock of reserves. To give some idea of the consequences of an estimated reserve base, it is typically compared to another physical quantity, projected consumption, giving rise to conclusions such as, we have n years' worth of coal, or iron, or whatever, left, at current or projected rates of consumption.t

Now a physical measure like reserves makes no sense for a nonextractive commodity, since we can, at a cost, produce as much as we want. Except in the very short run, "reserves" are not important. But looking more closely at extractive resources, the simple distinction begins to blur. That is, it is not clear that there is really a limited stock, at least one corresponding to reserves. Reserves are defined as the known amounts of a mineral that can be profitably recovered at current prices--for

tone of the best examples of this type of analysis is Population, Resources, and the Environment (1972), a report, edited by R.G. Ridker, of the U.S. Commission on Population Growth and the American Future. 
the mineral and the inputs used in extracting and processing it. $t$ obviously, then, reserves can be expanded by, to cite two important possibilities, discoveries of new deposits, and technical change which converts formerly uneconomic materials, such as ores with low metal content, into "reserves". We might say that the stock of an extractive resource can be augmented by investing in information, just as the number of effective units of labor can be by human capital formation--or as, for that matter, the supply of any nonextractive commodity can be. But if this is true, then the economic concept of scarcity, rising price, becomes significant for extractive natural resources as well as for these other items. The point is that for most if not all resources it is difficult to speak precisely about physical scarcity, either because we are uncertain about the extent, location, and quality of deposits, or because of ambiguities in the definition of ultimately recoverable reserves. Coal deposits, for example, though subject to less uncertainty than those of oil, gas, and most metalic minerals, are (necessarily) rather arbitrarily reckoned as consisting only of those of at least a given thickness of seam, and at most a given overburden of soil.t† The economic measure, price, then is a kind of summary statistic, reflecting a precise outcome of the conflicting influences on an unknown and perhaps unknowable physical magnitude.

The similarity of extractive to nonextractive resources may be a bit overdrawn. One could object that in the long run, extraction is bound by the finite stocks of minerals in the earth's crust. And long before these limits are reached, it is likely that incremental energy and environmental costs of extraction would become prohibitive. In the next section I shall set out a fairly traditional model of competitive extraction under certainty, i.e., a model that does not explicitly include investment in augmenting the resource stock. But later on I consider, less formally, how results might be affected by such augmentation. And in succeeding sections investment in reserve creation via exploration is made endogenous to the model.

The purpose of the next section's model is to bring out the relationships among a number of different economic scarcity measures that have been proposed for resources. I have referred to rising price as "the" measure of scarcity, but as we shall see, resources are different. There are at least two candidate price measures: the ordinary market price, and something that might be called a pure scarcity rent, the value of the unit of the resource "in the ground". Further, in the most influential study to date, that by Barnett and Morse, still another measure, the unit cost of extractive output, is emphasized. This in fact derives from perhaps the earliest scarcity theorist, Malthus,

tThis is the generally accepted definition, as explained in greater detail by Schanz (1976), drawing on U.S. Geological Survey publications and practice.

+ For precise specifications, see Darmstadter (1971). 
who believed that increasing agricultural output would require ever increasing "doses" of labor and capital, and also from Ricardo, who extended this conclusion to mineral output.t A simple model of optimal extraction by a competitive firm will not only bring out the relationships between these measures, but will shed some light on how each is affected by changes in the resource stock.

Broadly speaking, the conclusion is that each is well behaved, in the sense that it is generally (though not always, as we shall see) negatively related to the size of the stock. That is, the smaller the stock, the higher the price (rent, cost), and the larger the stock, the lower the price (rent, cost). But it does not follow that all three are equally sensitive or accurate measures of scarcity. This raises the question, what properties should such a measure have? In the remainder of this section I propose an answer that enables us to discriminate at least among cost, price and rent. Also, I attempt to justify, briefly, the statement made at the outset that an inquiry into the meaning and measurement of scarcity may be worth while.

Perhaps the two key questions about natural resource use that have emerged in the recent theoretical literature are, (1) is the time pattern of extraction produced by a competitive market socially efficient? and (2) how do various sources of market imperfection--monopoly, externalities, etc.--distort the competitive pattern?t Implicit in these questions is the possibility that market-determined rates of extraction could be too slow, as well as too rapid. So in a sense my concern with scarcity is a restricted one. It assumes that the underconsumption of resource stocks is less of a problem than their overconsumption. Two things can be said about this. First, there is no presumption that (existing) markets do, on balance, overconsume; this has not been demonstrated in the literature. Second, however, it seems reasonable to worry more about the consequences of this possibility. As Common (1975) has put it:

Depleting finite stocks of fossil fuels closes our future options in a way that depreciating a capital stock does not, in that the former is irreversible while the latter is not. Given labour and natural resources, capital equipment $c a n$ be created from

+For a clear and informative discussion of the views of the classical economists, see Barnett and Morse (1963), pp. 51-71. t+See the several studies in the Review of Economic Studies Symposium on the Economics of Exhaustible Resources (1974). Resource market imperfections are also classified and analyzed by Sweeney (1976) and Kay and Mirrlees (1975). Nordhaus (1973b), Solow (1974a), and Heal (1975) consider in particular the problems caused by the lack of futures markets. 
scratch: if, today, the world's entire capital stock were destroyed, it could be recreated. Given labour and capital equipment, natural resources cannot be created: if, today, the world's entire stock of fossil fuels were destroyed, it could not be recreated.

I have suggested that natural resource stocks can, in a sense, be augmented, but that does not really counter common's point. It is precisely the possibility of substituting producible capital, like machines or knowledge, for nonproducible materials, like highly concentrated ores, that allows us to effectively augment resource stocks. And for some types of resources, like unique natural environments, even this may not be possible. Once the redwood forests, or the Grand canyon, are gone, they are gone; they are irreplaceable.t The point is that a concern with natural resource scarcity, which seems to be shared by a wide segment of the general public, is not entirely irrational, however irrational some of the arguments motivated by this concern appear to be. I need hardly add that this does not imply that investigations into possible sources of over-conservation should not be undertaken. But in this paper I am simply trying to respond to the concern about impending exhaustion by indicating how it might be reflected in some alternative measures.

If it is agreed that a measure of scarcity may be of interest, what properties should it have? Let me propose a very simple answer. A measure of a resource's scarcity should have just one essential property: it should summarize the sacrifices, direct and indirect, made to obtain a unit of the resource. This appears to concentrate on the supply side, to the exclusion of demand, but in fact it does not. First, note the operative word, "made"; this implies a willingness to pay. Second, note the emphasis on indirect cost. In general, consumption of a unit of a resource today will have a direct cost, the labor and capital (and other resource) inputs required to extract and convert it, and an indirect cost, the value of future consumption foregone. After describing the relationships among cost, price, and rent with the aid of the next section's model, I shall argue that the unit cost of extractive output is, in theory, deficient as an indicator of scarcity, because it does not capture this indirect component. Price is the preferred measure, though there is something to be said for rent. And even unit cost comes back into the picture because, though it does not reflect the demand for, and value of, future output foregone, it typically moves in the right direction--increases--as a stock is depleted.

tA substantial literature on the economics of natural environments, which emphasizes the implications of the irreversibility of their consumption, has recently emerged. For perhaps the most complete statement, see Krutilla and Fisher (1975). 
There is in fact, as I shall show in sections 3 and 4 , an interesting duality between cost and rent. Where production conditions are such that cost increases with depletion, rent behaves erratically, and, if cost increases sufficiently, ultimately falls to zero. On the other hand, where cost does not increase with depletion, rent rises smoothly. Once again, then, price is the preferred measure, since it is in both cases negatively related to stock size. This suggests one other desirable property, hinted at earlier, for an economic measure: that it be related to stock changes in an intuitively plausible way.

The plan of the paper is as follows. In the next section, some elements of a model of optimal extraction are set out. Section 3 focuses on the much-discussed unit cost measure, noting its advantages and disadvantages. Section 4 takes up the behavior of resource rents and prices over time, and their relationships to stock changes. Finally, in section 5 investment in stock-augmenting exploration is introduced into the model. This has the advantage of leading to a practical proposal for estimating rent--though it also raises some troubling questions of market failure.

\section{OPTIMAL EXTRACTION AND THE RELATIONSHIP AMONG SCARCITY MEASURES}

In order to discuss sensibly the advantages and disadvantages of the alternative cost, price, and rent measures of scarcity, we need a clear idea of how these measures are related to each other. A simple model of optimal extraction by a competitive firm can provide this.t Further, it can be extended to show how they behave as a resource stock is depleted--or augmented, as through exploration--and how rent, ordinarily very difficult to observe, might be estimated. Now if we are interested in social scarcity--i.e., scarcity to society, not just to a single firm--it might seem preferable to model extraction to maximize a (social) objective like discounted aggregate consumers' plus producer's surplus from the resource. But as the necessary conditions that delineate the relations between cost, price, and rent are the same in either case, under standard assumptions, it will do just as well to analyze the slightly more convenient case of the firm.tt on the other hand, when it becomes important to broaden the focus to economy-wide depletion, I shall do this explicitly, as in parts of section 4 below.

tThe model is based in part on one in Peterson and Fisher (1977). + tThe original proof of something like this proposition is in Hotelling (1931). More recently it has been extended by Schulze (1974) and Sweeney (1976), among others. 
A key construct in the model is an extraction production function,

$$
Y=f(E, X, t)
$$

where $Y$ is extractive output, $E$ is effort (an index of labor and capital) devoted to extraction, $\mathrm{X}$ is the resource stock, and $t$ is time. The function is assumed to have the normal concavity in $\mathrm{E}$, i.e.,

$$
\mathrm{f}_{E}>0, \mathrm{f}_{\mathrm{EE}}<0
$$

Also, and very important, I assume a positive "stock effect" on output, i.e., $\mathrm{f}_{\mathrm{X}}>0$ and $\mathrm{f}_{\mathrm{EX}}>0$. In other words, with a larger stock, more output is obtained for a given effort and also for a given increment of effort. It is in fact this stock effect that drives costs up as a resource is depleted. It is possible to think of processes that do not exhibit the property-for example the extraction of salts from sea water--but they are not typical. As John Stuart Mill observed, mineral extraction costs rise because "shafts must be sunk deeper, galleries driven further", and so on.t similarly, for the most important resource in value terms, oil, decreasing pressure as a well is depleted requires increasing inputs of effort. I emphasize all this because many, if not most, of the recent contributions to the theoretical literature on natural resource depletion assume, explicitly or otherwise, no such stock effect--in terms of our model, $\mathrm{f}_{\mathrm{X}} \equiv \mathrm{f}_{\mathrm{EX}} \equiv 0$. This, in turn, has, as we shall see, implications for the behavior of rents and prices, as well as costs, as a resource is depleted.

The firm's objective is to maximize the present discounted value of its profits from sales of the resource. It does this by choosing a path of extraction subject to nonnegativity restrictions on effort, $E \geq 0$, and to the finite stock constraint,

$$
X(t)=X(0)-\int_{0}^{t} Y(\tau) d \tau, \quad X(t) \geq 0,
$$

tThe quotation from Mill is taken from Barnett and Morse (1963), p. 67 . 
where $x(0)$ is the initial stock. $\dagger$ Differentiating equation (2) with respect to time we obtain the system equation for the state variable $\mathrm{X}$,

$$
\frac{d X}{d t}=-Y(t)
$$

The formal statement of the firm's problem is

$$
\max \int_{0}^{\infty}[\operatorname{Pf}(E, x, t)-W E] e^{-r t} d t,
$$

subject to the nonnegativity restrictions and the system equation (3), where $\mathrm{P}$ is the price of the resource (a parameter to the competitive $f(r m), w$ is the wage of effort, and $r$ is the rate of discount.

The problem is now in a form suited to the application of the maximum principle of Pontryagin et al. (1962). The Hamiltonian equation is

$$
H=[P f(E, X, t)-W E-q Y] e^{-r t},
$$

where $\mathrm{q}$ is the costate variable attached to the constraint on the state variable $x$. It may be interpreted, as in other constrained maximization problems, as the change in the optimal value of the objective function resulting from a small change in the constraint. In particular in this problem $\mathrm{g}(\mathrm{t})$ is the effect on (discounted) future profits of removing a unit of the resource from the stock at time t.+† The maximum principle states that the control variable $\mathrm{E}$ must be chosen to maximize $\mathrm{H}$. Differentiating $H$ with respect to $E$ we obtain

$$
\mathrm{H}_{\mathrm{E}}=\mathrm{PY}_{\mathrm{E}}-\mathrm{W}-\mathrm{qY} \mathrm{Y}_{\mathrm{E}} \text {, }
$$

†For the time being I assume a known, initial stock to be depleted, with no possibility of augmentation as through exploration.

†+For an interpretation of dual variables as shadow prices in nonlinear programming, see Balinski and Baumol (1968). 
and, ignoring corner solutions and setting the result equal to zero,

$$
P=W / Y_{E}+q \text {. }
$$

This is an important result, but before I discuss it let me briefly say something about the technique used to obtain it. $t$ The basic principle is that we solve a complicated problem-choosing an entire time path of a variable--by breaking it down into a series of simple ones, choosing, in each short interval of time, a desired level for the variable.

The net return or profit to the resource-extracting firm, in a short interval $d t$, is ( $P Y-W E) d t$. The choice of $E$ in the interval should obviously be influenced by its impact on this quantity. But it should not be influenced solezy by this, because it also has an impact, as seen from equations (1) and (3), on depletion of the stock. This is essentially what equation (5), the Hamiltonian, suggests. The right-hand side of equation (5), (PY $-W E-q Y) e^{-r t}$, is just the (rate of) flow of profit due to current extraction (PY - WE), plus the (negative) value, in terms of the objective function, of depletion of the stock due to current extraction, qY--all appropriately discounted back to $t=0$. Central to this explanation is of course the interpretation of $q$ as the effect on the objective function of removing a unit of the resource from the stock, where $\mathrm{Y}$ represents the number of units removed.

Now let us return to equation ( 7 ). What it tells us is that, at all points along the firm's optimal extraction path, the market price $P$ is equated to the sum of the marginal cost of current extraction, $W / Y_{E}$, and the marginal loss in profit from future extraction, $q$. Note that had we assumed the firm to choose $E$ to maximize current return, the resulting necessary condition would have been the conventional $P=W / Y_{E^{\prime}}$ or price equals marginal cost. Note also that the divergence of price from marginal cost in a resource market does not arise from any market imperfection.

I have already given a couple of interpretations of the costate variable $q$. Now let me give another: $q$ is the rent to a unit of the resource, the difference between what is received by the resource owner, P, and what is paid out to contractual

†For further details see the intuitive development of Dorfman (1969) and the more rigorous one of Arrow and Kurz (1970). 
inputs, $\mathrm{W} / \mathrm{Y}_{\mathrm{E}}{ }^{\dagger}+$ So we have the following simple relationship between cost, price, and rent: price equals marginal cost plus rent, where $q$, the rent, is our desired measure of the indirect or opportunity cost of resource extraction.

This would seem to settle the question of which measure of scarcity is "best". Price, which reflects both the direct and indirect sacrifices required to obtain a unit of the resource, would seem to fit the bill. But here I am going to get very slippery and suggest that it depends on what one means by "resource". Is a resource the raw material in the ground? or is it the extracted, or extracted and converted, product? If the latter, then price is the appropriate measure of scarcity. But if the former, as Brown and Field (1976) argue, the extractioncost component of price is not relevant and rent is the appropriate measure.††

However one views this matter, rent clearly has a role in any assessment of scarcity. But as I shall show in section 4 below, rent as an indicator of scarcity has the disturbing property of sometimes decreasing as the resource stock decreases. In section 4 I spell out the circumstances in which this can occur. But first, I consider some problems with the unit cost measure.

\section{PROBLEMS WITH THE UNIT COST MEASURE}

Before turning to the problems with unit cost, let me start on a positive note. This measure, as Morse (1976) has observed, is suggested by the classical economists' concern that the natural resource sector would draw ever increasing amounts of labor and capital from other sectors, exerting a drag on growth. This seems to me a reasonable concern, and sufficient motivation for the cost calculations reported by Barnett and Morse (1963) and Barnett (1976). It is true, as Brown and Field (1976) have pointed out, that as richer deposits of a mineral are depleted, technical change in methods of extraction and conversion can offset the tendency to higher costs that would otherwise result from the movement to thinner deposits. The same sort of offsetting effect has probably also been produced by economies of scale in working the thinner deposits, which typically occur in larger concentrations. But in any event it seems legitimate to try to sort out these several effects. Ceteris paribus, it should be true that depletion of higher grade ores leads to a rise in the unit cost of mineral production. The potential for technical change and economies of scale is not inconsistent with

tStill another term for $q$ is marginal user cost, due to scott

(1953). It corresponds also to Nordhaus's (1973a) royalty, and Solow's (1974a) net price.

†TThis distinction is drawn also by Smith (1976). 
this proposition, and indeed is worth exploring, not only for the purpose of interpreting our cost data, but also for what it can tell us about these processes in the natural resource sector and in the economy generally.

I do however see a number of difficulties with the unit cost measure, both theoretical and empirical. One is that unit costs of production (or extraction) do not reflect anticipated future scarcity. It is perfectly possible, in theory, for unit costs to remain stable--and at a very low level--as a resource approaches exhaustion. Now it must be noted that this phenomenon is more a feature of highly simplified neoclassical models of optimal extraction than one of extraction in the real world. There, as I have suggested earlier, following Mill, a positive stock effect $\left(\mathrm{f}_{\mathrm{X}}>0, \mathrm{f}_{\mathrm{EX}}>0\right)$ means that costs will rise as the stock is depleted. To see how this works, recall that marginal extraction cost is given, in our model, by the expression $W / E_{E}$. Now, as $X$ decreases, $f_{E}$ decreases:

$$
\frac{\partial\left\{\frac{\partial f}{\partial E}\right\}}{\partial X}>0,
$$

so the marginal cost is driven up. Conversely, an increase in $\mathrm{X}$--caused for example by new information suggesting that $\mathrm{a}$ resource deposit is larger than originally believed, or by technical change that creates reserves out of formerly uneconomic materials--results in an increase in $\mathrm{f}_{E}$ and consequently a decrease in marginal cost $W / f_{E}$. But it must be acknowledged that future scarcity is not explicitly captured by any measure of current extraction costs. A positive stock effect merely pushes it in the right direction.

Another difficulty with unit cost, an empirical one, is that it is not readily observed. It must be constructed, as Barnett and Morse (1963) have done, from series on labor and capital inputs and extractive outputs. This gives rise to problems of aggregation. One, well known from investigations in another branch of economics, is: how is heterogeneous capital to be aggregated into a single input series? Another, noted by Brown and Field (1976), has to do with the aggregation of the various input series: "whereas the metals output series [in Barnett and Morsel appears to be at the extractive level, the metals employment data includes some undetermined fractions of workers in the separate processing sectors" (p.9). These are serious problems. The moral, I think, is not that we should abandon cost estimation, but simply that we recognize that it may not be a straightforward procedure. 
Resource Scarcity and the Environment

But perhaps the most serious difficulty with this measure, and one that was emphasiz@d at the recent Resources for the Future Forum on the Economics of Natural Resource Scarcity, $\dagger$ is that it does not fully reflect the effects of resource use on the environment. This is not a new point. Barnett and Morse (1963), in their pathbreaking study of trends in unit costs and prices of scape disfigurement, were not reflected in their calculations. If, as many people believe--though the time series evidence is scanty--such disruptions of the environment have been growing over time, then results like those of Barnett and Morse, which indicate a relative decline in the unit cost or price of extractive output, need to be reconsidered. That is, although the private cost has declined, the social cost may not have. Note, by the way, that failure to reflect environmental effects is a problem for any conventional measure of scarcity. I discuss it here because it has recently (see footnote) received attention with respect to cost measures.

Barnett (1976) has in fact reconsidered this question, and provides a partial answer to the concern about environmental cost. Recognizing the difficulty of estimating pollution damages, he looks at current and projected future costs of abatement implied by the recent clean air and water standards of the U.S. Environmental Protection Agency. Of course, even with these standards there will remain some pollution and other environmental disruption. But laying these aside for the moment, what can be said about the costs of achieving the standards? It turns out that, although these costs are growing both absolutely (in 1974 dollars) and relatively (to GNP), they will still be quite small (3\% of GNP) by the year 2000. Put another way, "we would have to give up less than a tenth of one percentage point in annual growth of national output to pay for this active abatement policy" (p. 3-1).

This relatively complacent view can be challenged on a number of grounds. The basic problem, as it has been stated by Krutilla (1976), is that to use an extractive natural resource like coal, say, it is generally necessary also to use a common property resource, like air or water. Implicit in Barnett's calculations is the possibility of uncoupling these joint products. That is, the idea is that it should be possible to produce and consume increasing tonnages of coal without at the same time "consuming" increasing amounts of clean air. This seems plausible with respect to many conventional pollutants, such as, for example, large particulates from coal burning power plants. But if Krutilla's p.int has any force, it is precisely that there may be a rather rigid relationship between goods and some bads. Again taking coal as our example, the buildup of carbon

†Forum on the Economics of Natural Resource Scarcity, Resources for the Future, Washington, D.C., October 18-19, 1976. 
dioxide in the atmosphere due to the combustion of coal (and other fossil fuels) may be a problem that cannot be dealt with by any conceivable abatement technology because it proceeds from the basic chemistry of combustion.t In fact, this is recognized by Barnett, along with radiation and nuclear waste storage, as a possible exception to his broad conclusion that pollution can be taken care of by a growing GNP.

Mention of radiation and nuclear waste suggests a more general point. Technical change, which as documented by Barnett and Morse and others has played such an important role in relaxing natural resource constraints, has in some ways put more of a burden on the environment. We are now becoming concerned, for example, about trace metals and other new and exotic chemical contaminants, possible carcinogens, in drinking water and some agricultural products, as stressed by Page (1976). Some of these substances may be sufficiently toxic that virtually complete abatement, or prohibition of discharge, will be required by the authorities concerned. And complete abatement can of course be very costly. A closely related point has to do with threshold levels for various pollutants. As suggested by Mishan (1976), ozone depletion and oil in the oceans, to take two examples, may not register until critical accumulations have been reached. Neither the damages nor the costs of preventing them will be taken into account by calculations like those presented earlier in this section.

Barnett has suggested an answer to the concerns about increasing amounts of conventional pollution, which may be applicable to the newer, more exotic forms as well. It is that, just as substitution in production and consumption, and technical change, have prevented the unit costs of extractive output from rising, they may do the same for pollution abatement. In order to meet a given air quality standard, for example, it will not be necessary to remove an ever increasing proportion of the sulfur from coal. Instead, cleaner sources of power may be substituted for coal over time, a less energy-intensive mix of goods may be consumed, or perhaps the sulfur can be removed cheaply from the coal with the aid of a new technology developed for the purpose.

A resource optimist would emphasize this line of reasoning, along with the relatively modest costs of achieving a substantial degree of cleanup even with currently known technologies. A resource pessimist, on the other hand, would perhaps be impressed by the difficulty in breaking the historical links between consumption of extractive and common property resources, and also with the dangers posed by some of the newer pollutants, which

†For a discussion of relationships between fossil fuel combustion, carbon dioxide in the atmosphere, and global climate, see Nordhaus (1976). 
may be highly toxic even in minute quantities. It seems fair to say that, in determining to what extent conventional measures of the cost of extractive output may need to be modified to reflect environmental concerns, we are confronted with a major research task. I think the key question--and it is an empirical one--is, to what extent can processes generating the "new pollution" be substituted away from, through technical change or otherwise?

\section{THE BEHAVIOR OF RENTS AND PRICES OVER TIME}

The result that rent need not rise at the rate of interest, or even monotonically as a resource is depleted, follows almost immediately. To see this, consider the equation for the evolution of the shadow price or rent, $q$, in the model: $\dagger$

$$
\dot{q}=r q-\hat{H}_{x} \text {. }
$$

Substituting for $\hat{H}_{X}$, the partial derivative of $\hat{H}$ ( where $\hat{H}=H e^{r t}$ ) with respect to $x$, and rearranging terms, we obtain

$$
\dot{\underline{q}}=r+\left(1-\frac{p}{q}\right) Y_{X}
$$

In other words, the rate of change of rent, $\dot{q} / q$, is equal to the rate of interest, $r$, only if there is no stock effect--i.e., only if $\mathrm{Y}_{X}=0$--or if there is no marginal extraction cost, i.e., $\mathrm{P}=\mathrm{q}$. In the general case in which these conditions do not hold, what does equation (9) tell us about the behavior of rent over time? Assuming $\mathrm{Y}_{\mathrm{X}}>0$, and since $\mathrm{P}>\mathrm{q}$, the right-hand side of equation (9) must be less than $r$. The pure return to holding a unit of the resource in the stock over a short interval of time, $q / q$, is less than the return on an alternative investment, given by $r$, because there is value, in the form of reduced extraction costs, to holding a unit "in the ground". And note that the rate of change of $q$ not only is not equal to $r$, in general; it may even become negative.

I think these results are worth emphasizing because they run counter to a fairly commonly held notion that in an optimal program, rent, or the shadow price of an exhaustible resource,

\footnotetext{
tAgain, see Arrow and Kurz (1970) for a derivation of this equation.
} 
rises over time as the resource is depleted, and moreover rises at precisely the rate of interest. As I have shown, the latter will occur only in the special case in which there is no stock effect. As for the possibility that rent as an indicator of scarcity is not well behaved, i.e., does not rise as the stock shrinks, this can be demonstrated more strikingly with the aid of a slightly different model and different definitions of resource and rent.

Let me start by recalling the classic concept of a resource rent, due to David Ricardo. Ricardo argued, in essence, that rent was just the difference between the payment to some resource input, like a parcel of good agricultural land, and the (labor and capital) costs of producing from it. Rent could persist, even in a competitive equilibrium, if the good land were in limited supply relative to demand. That is, if demand were sufficient to call into production poor land as well, the cost of production and hence the price of the product would be above the cost of production from the good land, the difference constituting a rent to the land. Although agricultural land is generally used to illustrate this concept, Ricardo noted that it applied to mineral resources as well. These too vary in "fertility", some being richer or more accessible than others. But as Barnett and Morse $(1963$, p. 64) also observe, the Ricardian rent to a mineral, or the land on which it is found, is not a payment for the exhaustion of the mineral. After all, even if the mineral were replenishable, like agricultural land, Ricardian rent would arise as long as market demand in any period could not be met by production from the richest and most accessible units alone. Conversely, as we shall see, even where production in any period depends only on a single (large) deposit, with constant marginal and average costs of extraction, so that there is no $\mathrm{P}^{\mathrm{i}}$ sardian rent, a scarcity rent like $\underline{q}$ in our model will exist.

A couple of simple diagrams will bring out these distinctions more clearly. In Figure 1 , the equilibrium relationship $\mathrm{P}=\mathrm{W} / \mathrm{f}_{E}+\mathrm{q}$ is illustrated by the intersection of the price line (P) with the curve $\left(W / f_{E}+q\right)$. At the equilibrium output $\mathrm{Y}=\mathrm{Y}^{*}$, there is, in general, a positive scarcity rent $\mathrm{q}$. But on all of the infra-marginal units, there is also a Ricardian rent, the shaded difference between price and cost, where $q$ is regarded as a part of the cost--which of course it is, whether paid by the producer to the owner of the resource rights, or simply imputed if producer and owner are one and the same.

Now consider a somewhat different case, in which all of the economy's production of a resource, in any period, is at constant marginal and average costs, from a deposit or deposits of constant quality. The necessary conditions, namely

$$
\text { (i) } P=W / f_{E}+q \quad\left(W / f_{E}=\text { constant }\right)
$$


and

$$
\text { (ii) } \frac{\dot{q}}{q}=r \quad \text { (no stock effects), }
$$

continue to hold, though the demand price $P$ is now $P=P(Y)$, where $Y$ is total output in the period; so condition (i) describes the intersection of a downward sloping demand $\left(\frac{\partial P}{\partial Y}<0\right)$ with a horizontal line.t Just above I suggested that production at constant costs will entail no rent in the sense of Ricardo, but it will entail a scarcity rent like $q$. The proof of the first part of this proposition is obvious. But what is the nature of the scarcity rent? Suppose, following Nordhaus (1973a), there exists some substitute for the resource--a "backstop", such as nuclear fusion reactors for fossil fuels--which

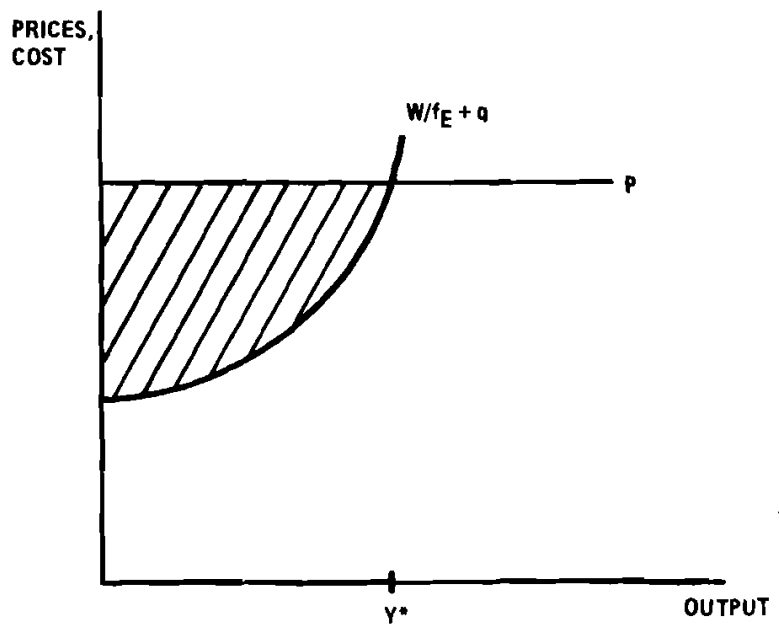

Figure 1. Equilibrium output and rent.

\footnotetext{
In all of this I am abstracting from the problem of monopoly. If the deposit is privately owned, I assume that the owner is a discriminating monopolist; if publicly owned, I assume optimization of something like producer's plus consumers' surplus. In either case, as I noted earlier, the necessary conditions are like (i) and (ii), and price includes no element of monopoly rent.
} 
produces the same final services as the resource, but at higher cost. Then, as Nordhaus also shows, the resource is used first, and its shadow price or scarcity rent--or royalty, as he calls it--is just equal to the difference between the cost or price of producing from the backstop $\left(\mathrm{P}^{\mathrm{B}}\right)$ and the cost of producing from the resource (C), at the switch date (T) from resource to backstop. At any time $t, 0 \leq t \leq T$, the royalty, equivalent to our $q$, is $\left(P^{B}-C\right) e^{-r(T-t)}$. That is, in the absence of stock effects, the royalty grows at the rate $r$ as the resource is depleted. So far, so good; as the stock shrinks, the rent rises. Note, by the way, that this rent in fact looks rather Ricardian. That is, although there is no true Ricardian rent, all production in any period coming from a constant quality deposit, the rent does reflect a cost difference.

But now suppose there is a second quality of deposit, poorer than the first but still more economical than the backstop. In this case, realistic certainly for most resources, it is easy to show that the rent or royalty does not rise monotonically as the resource is depeleted. Starting from the switch date from the first, good quality, deposit to the second, poor quality, the analys is is exactly as above. The royalty on the second deposit is $\left(P^{B}-C_{\partial}\right) e^{-r\left(T_{2}-T_{1}\right)}$, where $T_{1}$ is the switch date from the first to the second deposit, $\mathrm{T}_{2}$ is the switch date from the second to the backstop, and $\mathrm{C}_{2}$ is the (constant) cost of producing from the second. The royalty rises at the rate $\underline{r}$ to $\left(\mathrm{P}^{\mathrm{B}}-\mathrm{C}_{2}\right)$ at $\mathrm{T}_{2}$. The price of the second deposit at $\mathrm{T}_{1}$, when it enters production, is again the sum of marginal extraction cost and royalty, or $\mathrm{C}_{2}+\left(\mathrm{P}^{\mathrm{B}}-\mathrm{C}_{2}\right) \mathrm{e}^{-\mathrm{r}\left(\mathrm{T}_{2}-\mathrm{T}_{1}\right)}$. This price, call it $\mathrm{P}_{2}$, plays the same role, in turn, in the determination of the royalty on the first deposit as the price of the backstop plays in the determination of the royalty on the second. Thus the royalty on the first deposit is initially, at $t=0,\left(P_{2}-C_{1}\right) e^{-r T} T_{1}$, where $C_{1}$ is the (constant) cost of producing from the first deposit, and rises to $\left(P_{2}-C_{1}\right)$ at $t=T_{1}$. At this point, where the resource price is $\mathrm{P}_{2}$, and recalling that $\mathrm{C}_{1}<\mathrm{C}_{2}$, the royalty must fall, to $\left(\mathrm{P}_{2}-\mathrm{C}_{2}\right)$, on the second deposit. So the scarcity rent on the resource must fall.

Of course, one could take the view that the different quality deposits are different resources. And, in the absence of stock effects, the rent or royalty on each must rise--at the rate of interest. This is what I meant earlier, in suggesting that the result that rent need not rise monotonically as a resource stock is depleted depends on the definition of "resource". But my impression is that the same word--"copper", or "oil", or whatever--is commonly used to describe deposits of varying quality, so the result is not trivial. 
The analysis is easily extended from two to many different qualities of a resource, with each transition to a lower quality as the higher is depleted leading to a fall in the rent. Recalling the old distinction between intensive and extensive margins, as applied to agricultural land, we might say that the resource rent rises on the intensive margin and falls on the extensive. If and when resource extraction costs reach $\mathrm{P}^{\mathrm{B}}$, the price of the backstop, the rent falls to zero. All of this is represented in Figure 2. Market price always rises as the resource is depleted, cost rises in discrete jumps, and rent rises and falls, ultimately falling to zero when the market price reaches $\mathrm{P}^{\mathrm{B}}$. $\dagger$

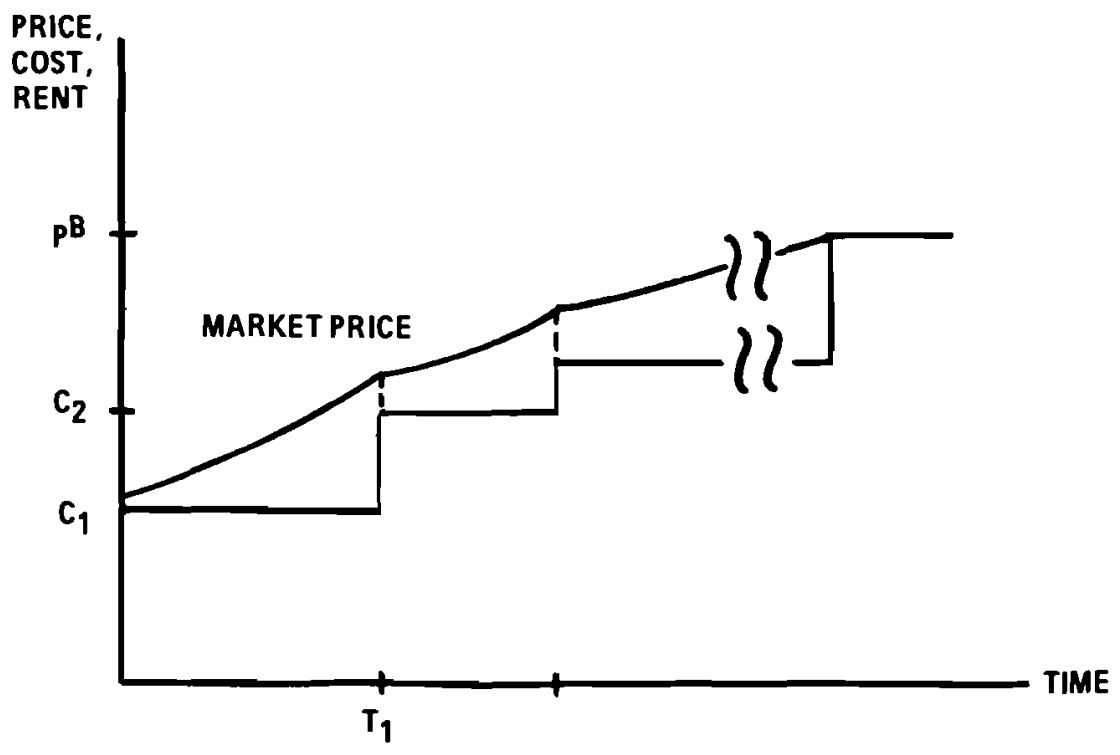

Figure 2. Behavior of price, cost, and rent over time.

†This diagram and the related analysis are essentially the same as in Herfindahl and Kneese (1974), one difference being that there the ultimate price, $\mathrm{P}^{\mathrm{B}}$, is the price at which demand for the resource equals zero. 
Another way of interpreting the result that rent vanishes is to consider the backstop as "average rock" instead of a new technology that substitutes for the resource. That is, ultimately all of the above-average concentrations of the resource are exhausted, and it is extracted from a virtually limitless supply of material in the earth's crust. $f$ It is intuitively plausible that, in this situation, there be no rent, Ricardian or other, to any unit, since one is as good, or as bad, as another, now and forever (almost).

Finally, note that we can approximate the continuous case described in the model of the preceding section and equations (8) and (9) by letting the time between cost jumps approach zero. Although the analysis there was for a single firm, and we are now talking about the resource industry, the result is the same. Rent evolves smoothly over time, according to an equation like (9), either rising or falling, but ultimately falling to zero if stock effects push up extraction cost indefinitely.

What conclusions can we draw, then, about the behavior of rent as the stock of a resource is depleted? First, the statement in the introductory section, that rent generally rises as the stock falls, is too sweeping. Where the costs of extraction are not affected by depletion, it is correct. But where they are--either in a continuous fashion as in the original model, or in a discrete fashion as in the transition to differentquality deposits in this section's model--there are conflicting tendencies; and if extraction costs rise all the way to the price of the backstop, the result is that rent falls to zero. Interestingly, there is a kind of duality between rent and cost as indicators of scarcity. Where cost is not a good indicator, rent is, and vice versa. That is, where there are no stock or quality effects, cost does not rise as a stock is depleted, but rent does. On the other hand, where these effects are present, cost is driven up, and rent rises along the intensive margin but falls along the extensive, ultimately to zero.

Thus far I have considered the evolution of rent as a stock is depleted over time. Another question is, what is the effect of a stock change on the initial value of the rent? In other words, instead of asking how rent behaves as a resource stock is depleted over time, I am now asking the comparative statics question: how is the initial value affected by a change on the initial stock? In symbols, what is the sign of $\frac{\partial q_{0}}{\partial X_{0}}$ (where $x_{0}$ refers to initial stock for the economy)? Notice that this introduces uncertainty. $x_{0}$ will be affected, as suggested in the introduction, by information about new deposits, or

tA similar model is considered by heal (1976). 
methods of producing a resource product from lower-grade materials. These would be positive effects, but one can also imagine better information leading to a downward revision of an estimated stock, as has recently occurred, for example, in the case of US offshore oil deposits. In any event, it is clear that the sign of $\frac{\partial \mathrm{q}_{0}}{\partial \mathrm{x}_{0}}$ is negative, as inspection of the expression for $g$ in this section's model of economywide depletion suggests.

Taking the simplest case, sufficient for our purposes, of depletion of a single grade of the resource up to replacement by a backstop, $q_{0}=\left(P^{B}-C\right) e^{-r T}$. The only thing affected by a stock change, $\mathrm{dx}_{0}$, is the switch date $\mathrm{T}$, since $\mathrm{P}^{\mathrm{B}}$ and $\mathrm{C}$ are technologically determined and $\underline{r}$ is a parameter to the resource sector. For a given pattern of demand for the resource, then, we have $T=T\left(x_{0}\right)$, where $\frac{d T}{d x_{0}}>0$. From this we obtain

$$
\frac{\partial q_{0}}{\partial x_{0}}=\frac{\partial q_{0}}{\partial T} \frac{d T}{d X_{0}}=(-r)\left(P^{B}-c\right)\left(e^{-r T}\right)\left(\frac{d T}{d x_{0}}\right)
$$

Since $\left(P^{B}-C\right)>0, e^{-r T}>0$, and $\frac{d T}{d x_{0}}>0$, for $r>0$ we must have $\frac{\partial \mathrm{q}_{0}}{\partial \mathrm{x}_{0}}<0$. A slightly more complicated analysis yields a similar but qualified result for price, as I shall presently indicate.

Now, what can be said of the relationship between stock change and price? Price appears to be generally well behaved, as seen for example in Figure 2. The equilibrium condition for both competitive firm and social planner, that price in any period equals marginal cost plus rent, ensures that price will always move in the right direction as a stock is depleted over time, pushed up by either rising cost or rising rent. The only remaining question is, how is the current market price affected by a change in the current estimate of the stock size?

In a world without a complete set of resource futures markets, the answer is not clear. But I think there is some presumption that price will continue to be well behaved. The crucial question is, how are price expectations formed? A number of theorists have recently considered this question, with interesting but not definitive results.t Here I just indicate

†See for example Nordhaus (1973a), Solow (1974a), Stiglitz (1974), Heal (1975), and Mishan (1977). 
the links, as I see them, in the chain connecting stock to price changes. This will enable us to identify the conditions under which current price increases (decreases) with a decrease (increase) in the estimated initial stock.

Suppose at $t=0$ the reserve base for a mineral resource increases, due to a new process that makes profitable the extraction and conversion of a very thin ore. This lowers the price expected to prevail in the future, when the new material will come on line--or, which is the same thing, the current rent--as indicated by equation (10). This, in turn, should lead either the public resource agency or private resource owners to expand current production, resulting (for given demand) in a fall in the current price. So, through the links of negative relations between initial stock and rent $\left(\frac{\partial q_{0}}{\partial \bar{x}_{0}}<0\right)$, and current output and price $\left(\frac{\partial P}{\partial Y}<0\right)$, a larger initial stock is associated with a lower current price.

The difficulty, or potential difficulty, lies in the effect on expected future price of a change in the current price. Let us define the elasticity of expectations as

$$
\varepsilon=\frac{\mathrm{dP}_{\mathrm{t}}^{\mathrm{e}}}{\mathrm{P}_{\mathrm{t}}^{\mathrm{e}}} / \frac{\mathrm{dP}_{0}}{\mathrm{P}_{0}},
$$

where $P_{t}^{e}$ is the price expected to prevail at time $t>0$ in the future. If $\varepsilon=0$, then the story is ended. The expected future price is determined solely by estimates of future demand and technology, which are not speculatively related to current price changes. But it is conceivable, and quite plausible, that $\varepsilon>0$. In this case, the reduction in $\mathrm{P}_{0}$ leads to a reduction in $\mathrm{P}_{t}^{\mathrm{e}}$, which leads in turn to a further expansion of current output and further reduction in $P_{0}$, and so on. Whether an equilibrium is reached should depend on the size of $\varepsilon$; if it is small enough, the current price changes should approach zero. But in any event, with these speculative effects we have perhaps too much of a good thing: current price overreacts to a change in the estimated initial stock. If, finally, $\varepsilon<0$, which is conceivable though not very plausible, then current price could react perversely, increasing with an increase in the stock. $t$

fFor a detailed analysis of the implications for competitive extraction paths of different expectation elasticities, though not in the context of a discussion of scarcity, see Mishan (1977). 
Although the possibility of speculative effects can cause problems for price as an indicator of scarcity, I don't think too much should be made of this. In the first place, the really bad result--current price varying positively with current estimated stock--could occur only if there were a sufficiently strong negative elasticity of expectations. But it is hard to tell a convincing story that would produce this result. In the second place, even the more realistic positive elasticity is not likely to persist. At some point beliefs about future demand and technology will call a halt to the round of speculative price decreases. Admittedly the net result could be some deviation from an efficient extraction path, but this is of greater relevance to the question whether the failure of a complete set of resource futures markets to exist will lead to inefficiency than to the narrower question whether price is likely to reflect scarcity.

\section{EXPLORATION AND EXTERNALITIES}

I have spoken of the possibility of augmenting a resource stock through investment devoted to the purpose, as in the exploration for new deposits. In this section such exploration is introduced into the model of section 2. This is not merely a formal exercise, however, as it leads to a new insight into resource rent and a practical proposal for estimating it. The basic idea is that, once we recognize that optimal depletion is not simply a matter of running down a known stock but involves the allocation of effort to finding new sources, we might conjecture that the rent, or indirect cost of a unit extracted today, will reflect not the loss in future income from that unit but the cost of finding another to replace it. This is precisely the result we shall obtain, as do also Brown and Field (1976). There does arise, however, an interesting problem involving externalities in exploration, which they do not consider.

It is important to recognize, before proceeding, just how strong the assumption about exploration is, and how it changes the earlier model. It makes the exhaustible resource into something like a renewable one--only more so, since the growth of a renewable resource is usually constrained by nature. And as with a renewable resource, a steady state, in which stock size and rent (the shadow price of a unit in the stock) do not change, becomes possible. In any event, the earlier criterion for judging a measure of scarcity--how it behaves as a stock is physically depleted--is no longer relevant, as the stock is potentially without limit. But effort is in fact required to extend the limit at any time, and this brings us back to the desirable property for a measure of scarcity suggested in the introduction: that it reflect the sacrifices made to obtain the resource. As we shall see, rent can be considered a good indicator in this sense, in a model with exploration--at least if one is interested in the resource in the ground. 
I don't intend to consider the dynamics any further here. Instead, I shall derive an expression that can be used to estimate the rent at any point in time. No doubt the associated view of exploration is too optimistic. On the other hand, section 2's model, which allows no growth in the resource stock, is probably too pessimistic. In any event, let us here develop the implications of the optimistic view. The relevance of either is of course an empirical matter.

Formally, the new element in the model is an exploration or discovery production function, $f^{d}\left(E^{d}, t\right)$, where $f^{d}$ represents new discoveries, measured in units of the resource, say tons, and $\mathrm{E}^{\mathrm{d}}$ is effort devoted to exploration. The idea is that the stock can be augmented by exploration, as well as diminished by extraction. The system equation then becomes

$$
\frac{d x}{d t}=f^{d}\left(E^{d}, t\right)-f^{e}\left(E^{e}, x, t\right),
$$

where the extraction production function is now written $f^{e}\left(E^{e}, x, t\right)$, and effort devoted to extraction, $E^{e}$.

The firm maximizes the discounted present value of profits

$$
\int_{0}^{\infty}\left[P f^{e}\left(E^{e}, x, t\right)-w^{d} E^{d}-w^{e} E^{e}\right] e^{-r t} d t
$$

where $W^{d}$ is the wage of effort $E^{d}$, and $W^{e}$ the wage of effort $E^{e}$. The necessary condition ( 7 ) is replaced by a pair of conditions corresponding to the two control variables $\mathrm{E}^{\mathrm{d}}$ and $\mathrm{E}^{\mathrm{e}}$ :

$$
\begin{aligned}
& -w^{d}+q f_{E}^{d}=0 \\
& P f_{E}^{e}{ }^{e}-w^{e}-q f_{E}^{e} e^{e}=0 .
\end{aligned}
$$

Equation (14) is just the same as equation (7), but from equation (13) we can substitute $w^{d} / f_{E}^{d}$ for $q$. This term, $w^{d} / f^{d}{ }^{d}{ }^{\prime}$ is clearly the marginal cost of exploration as $w^{e} / f_{E}^{e}$ is the marginal cost of extraction. 
Somewhat surprisingly, complicating the optimal extraction model by introducing exploration results in a simple suggestion for estimating rent. This also has implications for efficiency if, as suggested in the preceding section, we are worried about the way in which $q$ is determined by the expectations of agents in resource markets. Of course, an exploration cost or production function must still be estimated, but this is less of a venture into the unknown than forming an expectation of an entire price path.

The results are misleading, however, in appearing to banish uncertainty from the process of deciding how to allocate effort to exploration and extraction over time. Uncertainty is important in particular in exploration, which might in fact be viewed as fundamentally an exercise in reducing uncertainty. Two interesting strains of analysis have emerged in this area. One, following Allais (1957), considers exploration formally as a problem in sampling from an incompletely known size distribution of deposits. Another, more recent and exemplified by the work of Gilbert (1976), introduces uncertainty into relatively simple versions of optimal depletion models. Though further discussion is beyond the scope of this paper, these approaches are clearly central to a better understanding of the economics of exploration. $t$ But I think it is fair to say that the deterministic production function approach taken above also has a role to play.

A fruitful way to proceed here might be to introduce a stochastic term into the exploration production function. Exploration in one period could then have several effects. It would locate deposits, as in the deterministic case, but it could also reduce the effort needed to locate deposits in future periods by developing information about the geology of a region. In other words, it could shift the exploration production function--and perhaps also the extraction production function. Exploration might also result in a reduction in the variance of the stochastic term. If the agent undertaking the exploration were risk averse, such a reduction would be valuable. But in any event, a first approximation to the marginal user cost measure of rent might be obtained by looking just at exploration costs, as suggested by equations (13) and (14).

There is just one other issue I want to touch on, and that, as I noted at the outset of this section, is externalities in exploration. It is easily introduced through another extension of the basic model. This will also shed some light on the effects of uncertainty. We keep the same objective function as in equation (12), but change the system equation (11) in order to reflect the influence of past discoveries on the relationship between current exploratory effort and output. We do this

tAn informative presentation of recent work in probabilistic assessment of mineral prospects is found in Grenon (1976). 
by putting another argument, D, for cumulative past discoveries into the exploration production function. In symbols, this is

$$
\frac{d X}{d t}=f^{d}\left(E^{d}, D, t\right)-f^{e}\left(E^{e}, x, t\right)
$$

I shall consider the role of past discoveries presently, but first let us complete the structure of the problem and indicate the solution.

In addition to equation (15), there is a system equation describing the change in $D$ over time, which we write as

$$
\frac{d D}{d t}=f^{d}\left(E^{d}, D, t\right)
$$

The Hamiltonian for this problem is

$$
\begin{aligned}
H=\left[\left(P f^{e}-w^{d} E^{d}-w^{e} E^{e}\right)\right. & +q\left(f^{d}-f^{e}\right) \\
& \left.+p\left(f^{d}\right)\right] e^{-r t},
\end{aligned}
$$

where $p$ is the costate variable attached to the system equation for $D$. Differentiating $H$ with respect to the control variables $\mathrm{E}^{\mathrm{d}}$ and $\mathrm{E}^{\mathrm{e}}$, and setting the resulting partial derivatives equal to zero, we obtain

$$
{ }_{E}^{\mathrm{H}} \mathrm{d}=-\mathrm{W}^{\mathrm{d}}+{ }_{\mathrm{E}} E_{E^{\mathrm{d}}}^{\mathrm{d}}+{ }_{E}^{\mathrm{d}}=0
$$

and

$$
{ }_{E}{ }^{e}=P f_{E}^{e}-w^{e}-q f_{E}^{e}=0 .
$$

Equation (19) tells us, once again, that price should be set equal to the sum of marginal extraction cost and marginal user cost, or rent. But rearranging equation (18), we have a new expression for rent,

$$
q=w^{d} / t_{E^{d}}^{d}-p
$$


The first term on the right-hand side of equation (18') is just the marginal discovery cost. The second term, $p$, represents the shadow price of a unit added to the stock of discovered resources, $D$. The sign of $p$ will reflect the influence of $D$ on the exploration production function, but a priori the direction of the influence is not clear. It could be positive, in the sense that discovering another unit provides information that can reduce the effort input to future discoveries. This is a possibility I hinted at just above in discussing a stochastic exploration production function. But it could also be negative. Suppose there is a finite number of discoverable deposits of a mineral in a region. Then one more discovered today means one less discovered tomorrow. Not only that, but to the extent that the better deposits are discovered soon, there could be a substantial opportunity loss in depleting the "stock of discoveries". The upshot of these remarks is: p could be positive or negative, and the marginal discovery cost accordingly adjusted up or down. This seems to be a question that could usefully be addressed in specific cases, depending on the geology of the mineral and region.

Where do the externalities come in? With both of the effects just discussed, as noted first in a paper by Peterson (1975). Suppose a discovery does in fact provide information about where to look, and how, for further deposits. To the extent that this information is not kept within the firm making the discovery, it will benefit other firms, or even potential firms, searching for the mineral. The information spillover is an external economy, and if not appropriately compensated, will lead to a non-optimal allocation of effort to exploration by decentralized decisionmakers. In particular, it seems likely that firms will explore too little, each sitting back and waiting for the other to provide information, as Peterson (1975) and also Stiglitz (1975) have suggested.

The other effect, depletion of a stock of discoveries, is a classic common-property phenomenon. Clearly it is not just the firm making the discovery whose future prospects are diminished. All others are the poorer as well--there is that much less for them to find, and it will be that much harder to find. This creates an incentive for each firm to overexplore, as compared to what would be optimal if it enjoyed a secure tenure in all of the deposits of a mineral within a region. As is well known, one method of getting an individual economic agent to behave as if he were the sole owner, in a common-property setting--short of actually making him the owner, probably the best way to proceed where feasible--is to impose a tax that reflects the losses he imposes on others.

I conclude, then, that the determination of $p$, the adjustment to the marginal cost of discovery, or something analogous to it in an appropriate multi-party setting, is still more complicated than it appeared when we were concerned only with the effects of discovery internal to the firm. This looks like a 
very promising area for future research--though calculations of the behavior of discovery costs as proxies for rents need not wait on its completion.

\section{CONCLUSIONS}

The main point of this paper has been to examine the behavior of a number of proposed economic measures of a resource's scarcity as the resource is depleted or augmented (as through discovery of new sources) over time. A secondary point has been to examine the effect on the current value of each measure of a change in the current estimate of the resource stock. The proposed measures are price, cost, and rent. It turns out that price is preferred, always increasing (decreasing) as a stock is depleted (augmented) over time. Also, current price generally varies inversely with estimated stock at a moment in time-though this conclusion is subject to the condition that there not be a strong negative elasticity of expectations.

Cost and rent are sometimes well behaved as indicators of scarcity, sometimes not. It depends on the technology of extraction, and specifically on the strength of stock or quality effects on extraction costs. Where there are such effects, extraction cost rises as a stock or high-quality deposit is depleted, but rent is erratic, rising and falling in either discrete or continuous fashion, and ultimately falling to zero if extraction cost rises all the way to the price of the backstop for the resource. For a given quality deposit, and if there are no stock effects, cost does not rise as exhaustion nears, but rent does. So there is a kind of duality between cost and rent as measures of scarcity: where cost moves in the right direction, rent does not, and vice versa.

Another question considered in the paper is, to what extent must these conventional economic measures be adjusted to reflect the environmental effects of resource use? on the basis of currently available evidence, this remains an unresolved question. Calculations like those reported by Barnett (1976), which show a very small fraction of GNP required to attain fairly stringent air and water quality standards, suggest a modest adjustment, one that in most cases would not reverse the long term decline in unit costs.

This finding is strengthened by theoretical arguments for substitution and technical change in pollution control, as in resource extraction. On the other hand, one cannot, it seems to me, reject the hypothesis that the costs of dealing with a variety of new and exotic pollutants may be quite high, particularly as unknown thresholds are reached. And substitution and technical change may be less effective where, as with the accumulation of carbon dioxide from the combustion of fossil fuels, the bad is difficult or impossible to separate from the good. The whole question of the adjustment of scarcity measures to 
reflect the consumption of common property environmental resources, and in particular of the possibilities for substitution away from these resources, seems to me deserving of further research effort.

A final question deals with the behavior of rent--and one could extend the analysis to cost and price--when the resource stock can be indefinitely renewed by effort devoted to exploration. In this case, the relationship between rent and depletion is not particularly relevant. Complicating the formal model of optimal extraction by introducing the possibility of expanding the stock frees the economic measure from its tie to the physical. It turns out that rent on a mineral resource can be estimated, at least to a first approximation, by the marginal replacement cost, i.e., the cost of discovering new deposits. This is not a bad measure of scarcity, at least of the resource "in the ground", in that it reflects the sacrifices required to obtain the resource. It also raises interesting possibilities for empirical investigation--and challenging theoretical issues-because uncertainty about the size and location of deposits, and externalities in their exploration, indicate adjustments to the discovery-cost measure of rent. For example, the cost might be adjusted up or down, depending on whether a discovery carries a cost in that it depletes the "stock of discoveries" or a benefit in that it provides information about the prospects for future discoveries. Moreover, the question is complicated by the fact that neither effect is internal to the firm making the discovery.

\section{ACKNOWLEDGEMENTS}

I am grateful to Bengt Hansson, Geoffrey Heal, Alvin Klevorick, Harvey Lapan, and Karl-Göran Mäler for helpful discussions and comments on an earlier draft.

\section{REFERENCES}

Allais, M. (1957), A Method of Appraising Economic Prospects of Mining Exploration Over Large Territories: Aigerian Sahara Case Study, Management Science, 3 , July, 285-347.

Arrow, K.J., and M. Kurz (1970), Public Investment, the Rate of Return, and Optimal Fiscal Policy, Johns Hopkins Press, Baltimore, Md.

Balinski, M.L., and W.J. Baumol (1968), The Dual in Nonlinear Programming and its Economic Interpretation, Review of Economic Studies, 35, 3, 237-256.

Barnett, H.J. (1976), Scarcity and Growth Revisited, presented at the Forum on the Economics of Natural Resource Scarcity, Resources for the Future, washington, D.C., October 18-19. 
Barnett, H.J., and C. Morse (1963), Scarcity and Growth, Johns Hopkins Press, Baltimore, Md.

Beckerman, W. (1972), Economists, Scientists, and Environmental Catastrophe, Oxford Economic Papers, 24, 3, 237-244.

Brown, G.M., and B. Field (1976), The Adequacy of Measures for Signaling the Scarcity of Natural Resources, presented at the Forum on the Economics of Natural Resource Scarcity, Resources for the Future, Washington, D.C., October 18-19.

Common, M. (1975), Comments on the Papers by Robinson, and Surrey and Page, in D.W. Pearce and J. Rose, eds., The Economics of Natural Resource Depletion, Macmillan, London.

Darmstadter, J. (1971), Energy in the World Economy, Johns Hopkins Press, Baltimore, Md.

Dorfman, R. (1969), An Economic Interpretation of Optimal Control Theory, American Economic Review, 59, 5, 817-831.

Gilbert, R. (1976), Optimal Depletion of an Uncertain Stock, IMSSS, Stanford University, Stanford, Cal.

Grenon, M., ed. (1976), First IIASA Conference on Energy Resources, CP-76-4, International Institute for Applied Systems Analysis, Laxenburg, Austria.

Heal, G. (1975), Economic Aspects of Natural Resource Depletion, in D.W. Pearce and J. Rose, eds., The Economics of Natural Resource Depletion, Macmillan, London.

Heal, G. (1976), The Relationship Between Price and Extraction Cost for a Resource with a Backstop Technology, Belz Journal of Economias, 7, 2, 371-378.

Herfindahl, O.C., and A.V. Kneese (1974), Economic Theory of Natural Resources, Merrill, Columbia, Ohio.

Hotelling, H. (1931), The Economics of Exhaustible Resources, Journal of Political Economy, 39, April, 137-175.

Kay, J., and J.M. Mirrlees (1975), The Desirability of Natural Resource Depletion, in D.W. Pearce and J. Rose, eds., The Economics of Natural Resource Depletion, Macmilian, London.

Krutilla, J.V., and A.C. Fisher (1975), The Economics of Natural Environments: Studies in the Valuation of Commodity and Amenity Resources, Johns Hopkins Press, Baltimore, Md.

Krutilla, J.V. (1976), remarks at the Forum on the Economics of Natural Resource Scarcity, Resources for the Future, Washington, D.C., October 18-19. 
Meadows, D.H., et al. (1972), The Limits to Growth, Universe Books, New York.

Mishan, E.J. (1977), Does Perfect Competition in Mining Produce optimal Rate of Exploitation?, London School of Economics, unpublished.

Mishan, E.J. (1976), remarks at the Forum on the Economics of Natural Resource Scarcity, Resources for the Future, Washington, D.C., October 18-19.

Morse, C. (1976), remarks at the Forum on the Economics of Natural Resource Scarcity, Resources for the Future, Washington, D.C., October 18-19.

Nordhaus, W.D. (1973a), The Allocation of Energy Resources, Brookings Papers on Economic Activity, No. 3, 529-570.

Nordhaus, W.D. (1973b), World Dynamics - Measurement without Data, Economic Journal, 82, 1156-1183.

Nordhaus, W.D. (1976), The Climatic Impact of Long Run Energy Growth, presented at American Economic Association Meetings, Atlantic City, N.J., August 16-18.

Page, R.T. (1976), remarks at the Forum on the Economics of Natural Resource Scarcity, Resources for the Future, washington, D.C., October 18-19.

Peterson, F.M. (1975), Two Externalities in Petroleum Exploitation, in G.M. Brannon, ed., Studies in Energy Tax Policy, Ballinger, Cambridge, Mass.

Peterson, F.M., and A.C. Fisher (1977), The Exploitation of Extractive Resources, Economic Journal, 87, December (forthcoming).

Pontryagin, L.S., et al. (1962), The Mathematical Theory of optimal Processes, translated by K.N. Trirogoff, Wiley, New York.

Ridker, R.G., ed. (1972), Population, Resources, and the Environment, U.S. Commission on Population Growth and the American Future, U.S. Government Printing office, Washington, D.C.

Schanz, J.J. (1976), Problems and Opportunities in Adapting USGS Terminology to Energy Resources, in M. Grenon, ed., Eirst IIASA Conference on Energy Resources, CP-76-4, International Institute for Applied systems Analysis, Laxenburg, Austria.

Schulze, W.D. (1974), The Optimal use of Non-Renewable Resources: The Theory of Extraction, Journal of Environmental Economics and Management, 1, 1, 53-73. 
Scott, A.D. (1953), Notes on User Cost, Economic Journal, 63, June, $368-384$.

Smith, V.K. (1976), The Measurement of Natural Resource Scarcity, Resources for the Future, Washington, D.C., unpublished.

Solow, R.M. (1974a), The Economics of Resources, American Economic Review, 64, 2, 1-14.

Solow, R.M. (1974b), Intergenerational Equity and Exhaustible Resources, Symposium on the Economics of Exhaustible Resources, Review of Economic Studies, 29-45.

Stiglitz, J. (1974), Growth with Exhaustible Natural Resources: The Competitive Economy, Symposium on the Economics of Exhaustible Resources, Review of Economic Studies, 139-152.

Stiglitz, J.E. (1975), The Efficiency of Market Prices in Long Run Allocations in the Oil Industry, in G.M. Brannon, ed., Studies in Energy Tax Policy, Ballinger, Cambridge, llass.

Sweeney, J.L. (1976), Economics of Depletable Resources: Market Forces and Intertemporal Bias, U.S. Federal Energy Administration, Washington, D.C. 